\title{
Guerra y paz en Colombia: introducción al caso de las Farc
}

\author{
Guerra e paz na Colômbia: introdução ao caso das Farc \\ War and Peace in Colombia: introduction to the Farc Case
}

Sergio Quintero Londoño*

\begin{abstract}
Resumen - En este artículo se presenta la génesis del último ciclo de violencia vivido en Colombia (1946-2017), producto del enfrentamiento entre las Fuerzas Armadas Revolucionarias de Colombia (Farc) y el bloque hegemónico de poder, con el Estado como su mayor representante. El eje central de análisis aborda la acción coercitiva del Estado como un modus operandi que se presenta a lo largo de la mitad del siglo XX e inicios del XXI. El proceso de conciencia analizado a partir de la tradición marxista y algunos elementos de psicología social permiten ver las transformaciones de las Farc en el tránsito de Autodefensas Campesinas a una guerrilla orientada por una estrategia político-militar hacia la toma del poder. Finalmente, se expone de manera introductora la apertura de los diálogos de paz como síntesis de la contradicción, donde, al poner fin a la guerra, se abren posibilidades para la democratización política y económica del país.

Palabras clave: Colombia; Farc; guerrilla; Estado; Violencia.
\end{abstract}

Resumo - Neste artigo se apresenta a gênesis do último ciclo de violência vivido na Colômbia (1946-2017), produto do enfrentamento entre as Forças Armadas Revolucionárias da Colômbia (Farc) e o bloco hegemônico de poder, sendo o Estado seu maior representante. O eixo central da análise aborda a ação coercitiva do Estado como o modus operandi que se apresenta ao longo da segunda metade do século XX e início do XXI. O processo de tomada de consciência, analisado a partir da tradição marxista, e alguns elementos da psicologia social permitem ver as transformações das Farc de Autodefesas Camponesas a uma guerrilha orientada pela estratégia político-militar em direção à tomada de poder. Finalmente,

\footnotetext{
* Assistente Social na Universidad de Caldas - Colômbia. Doutorando em Serviço Social na Universidade do Estado de Rio de Janeiro. Membro do Grupo de Pesquisa Estado, Classes Trabalhadoras e Serviço Social no Brasil (NECLATSS). Integrante do Trabajo Social Crítico - Colômbia. Correspondência: Universidade do Estado de Rio de Janeiro - Faculdade de Serviço Social. Rua São Francisco Xavier, 524/ CEOI, $8^{\circ}$ andar, Bloco D - Maracanã, Rio de Janeiro. CEP: 20550-900. Email: <seranquilog@hotmail.com>.
} 
expõe-se de maneira introdutória a abertura dos diálogos de paz como síntese da contradição, em que, ao pôr fim à guerra, abrem-se possibilidades para a democratização política e econômica do país.

Palavras-Chave: Colômbia; Farc; guerrilha; Estado; Violência.

\begin{abstract}
This article presents the origins of the last cycle of violence in Colombia (1946-2017), a product of the confrontation between the Revolutionary Armed Forces of Colombia (FARC, in Spanish) and the hegemonic bloc of power, with the State as its main representative. The central point of analysis is the State's coercive action as a modus operandi that appears throughout the 20th century and beginning of the 21 st. The process of conscience, analyzed from the Marxist tradition's point of view and some elements of social psychology, show the transformations of the FARC from self-defense forces to a guerrilla oriented by a political-military strategy towards the seizure of power. Finally, it is presented an introduction to the opening of peace talks as the synthesis of contradiction, where the end of the war opens up possibilities for the political and economic democratization of the country.
\end{abstract}

Keywords: Colombia; Farc; guerrilla; State; violence.

\title{
Introducción
}

La historia de Colombia, al igual que la gran mayoría de los países latinoamericanos se inscribe en la historia del desarrollo capitalista periférico. Su particularidad obedece a que desde el siglo XIX, cuando se convierte en Estado-Nacional republicano, ha tenido que priorizar el uso de la violencia política para desempeñar el papel subsidiario a las economías hegemónicas del capitalismo central.

La tradición marxista, al indagarse sobre el modo de producción capitalista encuentra en el Estado un eje central para la comprensión del sistema, reconociendo que este puede y debe cumplir diversas funciones subsidiarias del capital. Mandel (1982) identifica tres funciones básicas del Estado (simultáneas y/o alternas), las cuales consisten en: a) ejecutar acciones represivas para el control social, b) implementar medidas legitimadoras que contribuyan en la cooptación de diversos sectores sociales y c) garantizar la reproducción ampliada del capital a partir de su intervención directa en la economía.

En el escenario político de Colombia, la forma de administración gubernamental se mantiene reducida al poder bipartidista de Liberales y Conservadores, haciendo del Estado un escenario que perfecciona su capacidad policiaca y militar para el ejercicio de la violencia (aliada a organismos internacionales), en detrimento de la garantía de derechos sociales. Durante las décadas de 1940 y 1950, la respuesta organizada de la clase trabajadora ante la violencia estatal y la negación de derechos toma diferentes formas, entre las que se destacan las autodefensas armadas y grupos guerrilleros, 


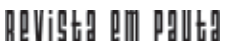

\} GUERRA Y PAZ EN COLOMBIA: INTRODUCCIÓN AL CASO DE LAS FARC - LONDOÑO, S. Q. \}

DOI 10.12957/REP.2017.30375

siendo las Fuerzas Armadas Revolucionarias de Colombia (Farc) el proceso más antiguo y conocido'.

La interpretación de la guerra es tan variada como variados son los actores que en ella se encuentran; de igual forma, en el campo académico se han enfrentado interpretaciones subjetivistas y estructuralistas; no obstante, en el presente análisis se adopta una interpretación en la que se muestra el origen y desdoblamiento de la guerra como una relación contradictoria entre sujetos y estructuras, propias del modo de producción capitalista:

Una de ellas considera que el conflicto armado, así como todas las manifestaciones de insurgencia o resistencia tienen como referente explicativo el orden social vigente que, sin duda, responde a las características esenciales del sistema capitalista, cuya existencia es reconocida en nuestra contemporaneidad como socialmente existente, con independencia de su valoración positiva o negativa, o de los entendimientos múltiples que hoy se presentan sobre sus transformaciones y efectos. (MONCAYO, 2015, p. 15)

En este orden de ideas, se debe entender la guerra como un desdoblamiento lógico que caracteriza las contradicciones del capital, que en el caso colombiano asume una forma particular (sin dejar a responder a la tendencia general). El carácter represivo del Estado asume una doctrina militar contrainsurgente de combate al enemigo interno, sustentado en la política internacional aliada al capital monopolista, que reprime y persigue las organizaciones guerrilleras, así como el pensamiento crítico y las organizaciones sociales de oposición.

Sin ser un documento histórico-cronológico, se abordan dos contextos históricos que permitan entender el surgimiento de las Farc y su momento actual. A continuación se desarrollará la premisa fundamental de que la historia de Colombia se inscribe en las relaciones contradictorias del capitalismo, dentro de las cuales, en el campo económico ha establecido algunas particularidades que son subsumidas por el movimiento general del capital, mientras que en el campo político, se prioriza la coerción y la violencia, consolidando un proceso de desarrollo capitalista vía "junker".

El análisis en cuestión constituye una interpretación cualitativa sobre el origen de uno de los actores de la lucha de clases en Colombia, para lo cual se recuperan documentos históricos y textos recientemente publicados en el contexto de posible fin de la guerra. A partir de la interpretación materialista de la historia, inspirada en la tradición marxista, se analiza el origen de la guerra como una expresión clara de la lucha de clases en un escenario particular del capitalismo periférico. Sin subvalorar los aportes

\footnotetext{
${ }^{1}$ Durante la segunda mitad del siglo XX, como organizaciones insurgentes en el campo militar, además de las Farc, se encuentran el Ejército de Liberación Nacional (ELN), el Ejército Popular de Liberación (EPL) y otras organizaciones extintas, como la guerrilla indígena Manuel Quintín Lame, el Partido Revolucionario de los Trabajadores (PRT), la Corriente de Renovación Socialista y el Movimiento 19 de Abril (M-19).
} 
de otros autores, se toman como referencias centrales para la interpretación del objeto a Nicolás Maquiavelo, Mauro lasi y Germán Guzmán. La exposición se presenta en 3 partes, a saber: i) Violencia política y constitución del capital, ii) Violencia insurgente y lucha de clases, y iii) Acabar la guerra para democratizar el país.

\section{Violencia política y constitución del capital}

Aunque Nicolás Maquiavelo es insuficiente para analizar plenamente la violencia política del siglo XX, al tener en cuenta su exposición, se encuentran tendencias que ayudan en la comprensión del carácter coercitivo del Estado colombiano.

La condición ideal en la que se debe ubicar un príncipe para gobernar debe ser la de amado y temido; sin embargo, al reconocer que la unión de estas características es una combinación inusual, Maquiavelo expresa la necesidad de inclinarse para conquistar la segunda. "Se responde que se quiere ser las dos cosas; pero, como es difícil conseguir ambas a la vez, es mucho más seguro ser temido primero que amado, cuando se tiene que carecer de una de las dos cosas" (MAQUIAVELO, 1986, p. 69).

Aunque advierte la necesidad de evitar el odio, es claro que el control coercitivo hace parte del comportamiento "necesario" para mantenerse en el poder del Estado. Para el autor italiano, ante la ausencia del poder centralizado, la sociedad puede caer en una anarquía que se alimenta del odio y las contradicciones de los hombres, impidiendo un avance en el desarrollo político y económico. La garantía de "estabilidad" se encuentra en el supuesto uso adecuado de la ley y las armas.

Según Maquiavelo, las leyes permiten una orientación en la conducta de los seres humanos, posibilitando su convivencia; sin embargo, por sí solas las leyes no tienen las condiciones para hacer cumplir los mandatos, pues constantemente surgen cuestionamientos e incluso levantamientos que, no sólo discrepan de ellas, sino que las pretenden destrozar para crear otras nuevas. "Debéis, pues, saber que hay dos maneras de combatir: una con las leyes y otra con la fuerza; la primera es propia del hombre, la segunda lo es de los animales; pero, como muchas veces la primera no basta, conviene recurrir a la segunda" (MAQUIAVELO, 1986, p. 72).

Por tanto, para garantizar la cohesión social y del Estado, quien tenga el poder debe hacer uso de la violencia, impidiendo cualquier tipo de violación a la norma que pueda vulnerar el orden establecido. Las armas deben ser el principal instrumento en la defensa del poder, y para ello se debe estar dispuesto a llegar hasta las últimas consecuencias.

La guerra es el camino necesario para mantenerse o vulnerar el poder de gobernar. Quien tenga el poder que le permita direccionar un país debe ser consciente de los peligros que corre, y debe identificarlos para po- 


\section{peVistg all paltg}

\} GUERRA Y PAZ EN COLOMBIA: INTRODUCCIÓN AL CASO DE LAS FARC - LONDOÑO, S. Q. \}

DOI $10.12957 /$ REP.2017.30375

der generar respuestas inmediatas que impidan el crecimiento del peligro. Conocer las comunidades y estar cerca de ellas permite observar los cambios que pueda sufrir, al igual que los planes conspirativos que se estén gestando. En tal caso, el ejercicio de la violencia se debe activar aniquilando cualquier vestigio insurgente, a manera de guerra preventiva.

Los cuales príncipes no solamente han de tener cuidado con los desórdenes que pueden desencadenarse en el momento presente, sino que han de prever los futuros y evitarlos con destreza: porque, teniendo precaución de que no ocurra ningún contratiempo en el presente, se prevé todo contratiempo venidero y se evita; porque el prevenir a distancia admite remedio, sin embargo, si esperamos a que el peligro se nos eche encima, es ya imposible aplicar remedio, porque el mal se ha hecho crónico. (MAQUIAVELO, 1986, p. 14)

Además del análisis político de Maquiavelo, es necesario tener en cuenta el momento histórico en que el capitalismo se instala plenamente en la región latinoamericana (primera mitad del siglo XX) y las particularidades político-económicas en la configuración de la burguesía periférica; esta contextualización abre una línea interpretativa para la violencia política en el marco del capitalismo.

De acuerdo a lo anterior, se debe prestar atención sobre tres elementos centrales que permiten profundizar el análisis; en América Latina: a) la burguesía periférica se consolida cuando el capitalismo monopolista se ha tornado hegemónico en la economía mundial, b) se presenta una asociación entre capital central y periférico, controlada por parte del primero sobre el segundo; c) las burguesías capitalistas periféricas no rompen con las relaciones socio-políticas y económicas de grupos y clases dominantes "precapitalistas" o no capitalistas. Estas tres características estarán determinadas por el uso de la violencia política de los sectores hegemónicos en contra de las clases subalternas ${ }^{2}$.

La división internacional del trabajo, y el lugar predeterminado que cumplen los países periféricos en la economía mundial, impiden que en las propiedades latifundistas se introduzca el pleno desarrollo técnico y tecnológico, al tiempo que se intensifican jornadas de trabajo sin la mediación de contratos laborales, negando los derechos más básicos como salario mínimo, salud, pensión, seguro de accidentes y prestaciones sociales. Grandes extensiones de tierra son concentradas en manos de terratenientes que, adheridos al pensamiento conservador y a la iglesia católica, se resisten a implementar formas de producción modernizadas en el campo.

La forma a través de la cual se explota la tierra y se ingresa en el mercado internacional hace que los trabajadores vendan su fuerza de trabajo

\footnotetext{
2 Para un análisis detallado sobre el desarrollo del capitalismo en América Latina, ver Aricó (1980), Cueva (1977), Fernandes (2009) y Mariátegui (2010).
} 
por debajo del valor necesario para su plena reproducción; tengan intensas y prolongadas jornadas de trabajo, mientras que la venta de materias primas en el mercado mundial se realiza con bajos precios, facilitando la reproducción del capital monopolista en los países centrales ${ }^{3}$.

Sobre la estructura político-económica de mediados del siglo XX, Antonio García (1972, p. 59) explica:

Desde el punto de vista de la economía empresarial, esos niveles de irracionalidad e ineficiencia se expresan en el hecho de que los grandes latifundios, acaparando un exceso de tierras, tienen una bajísima capacidad ocupacional y una exigua participación en el valor de la producción agropecuaria; y de que los minifundios, padeciendo una aguda escasez de tierra, deben soportar una elevada sobrecarga de mano de obra y tener una muy baja participación en el valor total de la producción, no obstante que su productividad por hectáreas es usualmente más elevada que en los latifundios. [...] En Colombia, las capas minifundistas, con el $5 \%$ de la tierra agrícola, debe ocupar el $58 \%$ de la mano de obra y contribuir con el $21 \%$ de la producción agropecuaria; y los grandes latifundios, con cerca de la mitad de la tierra agrícola (45\%), apenas ocupa el $4 \%$ de la mano de obra y contribuye con el $15 \%$ del valor total de la producción.

La combinación de características modernas y "premodernas" no solo obedece a la capacidad o incapacidad de las clases hegemónicas, sino también a la composición plural de los trabajadores y sectores insurgentes, que no se reducen al proletariado urbano industrial. La forma dependiente de la economía y el desarrollo político, inscrito en la dinámica inmanente del capital es el resultado del enfrentamiento entre una gama diversa de sectores de clases sociales y las propias contradicciones del capital bajo una estructura de poco desarrollo de fuerzas productivas, que se ha especializado en la transferencia de valor.

En Colombia, la configuración de la producción mercantil capitalista se instala principalmente en los centros urbanos durante los años 1920 y 1930, cuando se genera un primer intento de desarrollo industrial que, aunque incipiente y sin romper las formas tradicionales de explotación rural, consigue reestructurar en gran medida la composición del campo y la ciudad $^{4}$.

Con la ruptura de la hegemonía conservadora (1903-1930), y con el control del poder estatal por parte de la hegemonía liberal a partir de 1930, se inician reformas político-económicas que generan fuertes con-

\footnotetext{
${ }^{3}$ La forma de reproducción capitalista en América Latina se logra a través de lo que Marini denominó "superexplotación". Ver Marini (2012).

${ }^{4}$ Se estima que durante los años 20, la población rural constituye el 70\% de los habitantes del país, y la economía nacional se basa en agroexportaciones y extracción de materias primas. Según datos analizados por María Eugenia Martínez (1981), en el periodo de 1918 a 1928 Bogotá pasa de 144.000 habitantes a 235.000, Medellín de 80.000 a 120.000 , Cali de 45.000 a 124.000 y Barranquilla de 64.000 a 140.000 .
} 


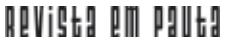

\} GUERRA Y PAZ EN COLOMBIA: INTRODUCCIÓN AL CASO DE LAS FARC - LONDOÑO, S. Q. \}

DOI $10.12957 /$ REP.2017.30375

tradicciones en la búsqueda de consolidar el modo de producción capitalista. Si en la vida rural los impactos de la Ley no 200 del 1936 (basada en la sentencia de la Corte Suprema de Justicia del 15 de abril de 1926) permiten parcialmente la apropiación de la tierra por parte de campesinos organizados, al tiempo que estimula el desarrollo capitalista agrario, en las ciudades, la consolidación de la industria y la nueva clase proletaria, regida con la naciente reforma laboral, tributaria y de educación, generan condiciones más avanzadas para una instauración plena del modo de producción y reproducción del capital, y con ello el enfrentamiento de clases que lo caracteriza.

El Partido Comunista, creado en 1930 e influenciado por la Tercera Internacional, intenta avanzar en la creación de Frentes Populares y procesos de unidad; como consecuencia de esta estrategia se crean las Ligas Campesinas, Sindicatos Agrarios, y procesos organizativos en la región del Sumapaz, Tequendama, Tolima, Huila y Valle. Además de la influencia comunista, algunos sectores radicales del liberalismo establecen contacto y avanzan en procesos organizativos con campesinos en diversas zonas, especialmente de la Región Andina.

La división del Partido Liberal en las elecciones presidenciales de 1946, lanzando dos candidatos (Gabriel Turbay y Jorge Eliecer Gaitán), permitió el triunfo de Mariano Ospina Pérez, quien ocupa la presidencia de la República en representación del Partido Conservador (1946-1950), ejecutando un proceso radical de contrarreforma (basado en la Ley $\mathrm{n}^{\circ} 100$ de 1944). A partir de 1946, el poder ejecutivo y legislativo conservador se caracteriza por estimular una oleada de violencia contra todas las organizaciones populares, especialmente contra los sectores de influencia liberal gaitanista y comunista; tarea en la que el ejército y policía desarrollan una evidente labor represiva dando inicio al periodo de "La Violencia"

El peligro que representa la alternativa política liderada por Jorge Eliecer Gaitán, con amplias posibilidades de triunfo en las elecciones presidenciales de 1949, radicaliza la reacción conservadora que, habiendo instigado la violencia desde 1946, se agudiza con el asesinato del caudillo el 9 de abril de 1948. Con los acontecimientos del Bogotazo ${ }^{6}$ la lucha de clases en Colombia adquiere nuevo nivel: por un lado se develan los alcances de las clases hegemónicas ancladas en los partidos políticos tradicionales con el ánimo de salvaguardar sus intereses oligárquicos; mientras que por otro lado se explicita la fuerza con la que podía reaccionar la clase trabajadora sometida a condiciones de pauperismo.

\footnotetext{
${ }^{5}$ De acuerdo con el análisis de "violentología", entre 1946 y 1953 se vivencia el periodo de "La Violencia" (con $\checkmark$ mayúscula) estimulado por las medidas represivas de los presidentes conservadores Mariano Ospina Pérez y Laureano Gómez, que arrojan como resultado más de 240.000 víctimas mortales.

"Se conoce como "Bogotazo" al levantamiento popular como forma de respuesta ante el asesinato de Jorge Eliecer Gaitán. Los enfrentamientos tuvieron como epicentro la ciudad de Bogotá, sin embargo, diversos autores, entre lo que se encuentra Jacobo Arenas (1972), argumentan su desarrollo e impacto nacional. Para muchos analistas, esta fecha es la que inaugura el ciclo de violencia que se extiende durante el resto del siglo XX.
} 
Desde el 1946, la acción violenta "legal" se encuentra bajo el comando del ejército y la policía, mientras que "Los Pájaros" y "Chulavitas", nombre con el que se conocían los grupos de pistoleros a sueldo, ejecutan "la violencia extra-legal". Como respuesta a los acontecimientos del Bogotazo, el régimen conservador depura las fuerzas militares, garantizando una cohesión interna que se extiende hasta 1958 sustentada en el Decreto ley 2311 de 1953; por su parte, el cierre del Congreso decretado en 1949 consolida las políticas represivas y excluyentes ${ }^{7}$.

La persecución hacia las organizaciones y poblaciones de influencia liberal y comunista se da en un ambiente de sevicia, recurriendo al terror como práctica cotidiana, tanto en el campo como en la ciudad. Decenas de relatos pueden ser reproducidos para demostrar la barbarie que caracteriza la violencia de los años 1940 y 1950, no obstante, una síntesis general podría ser reconocida en una carta escrita por campesinos del departamento de Antioquia en julio de 1951:

Hijos y padres caen asesinados en la oscuridad de la noche o a la claridad del día. Unas veces dormidos; ya limpiando sus sembrados o bien transportando sus frutos hacia el pueblo... Multitud de campesinos abandonan, unos sus chozas y sus huertas; otros durante semanas y semanas duermen en el monte sujetos a las inclemencias del tiempo. [...] Cadáveres de nuestros hermanos hemos tenido que dejar a la intemperie y huir. Hijos agónicos hemos tenido que reecoger en nuestros brazos. (GUZMÁN apud GUZMÁN; BORDA; UMAÑA, 2014)․․

Un análisis sistemático de "La Violencia" evidencia que esta es el medio para la concentración de la tierra, el desarrollo industrial capitalista, y la represión contra diferentes sectores de la clase trabajadora.

En el caso específico del sector campesino, principal víctima de la violencia, se pueden identificar tres consecuencias: a) grupos significativos de pequeños propietarios y jornaleros son asesinados (casi 300.000), b) otros son desplazados hacia la ciudades como fuerza de trabajo para la nueva industria (ubicando a casi el $70 \%$ de la población en la zona urbana), y c) otros se desplazan hacia el interior de la selva colonizando nuevas regiones, asumiendo medidas de autodefensa armada y grupos guerrilleros para evitar futuros ataques conservadores ${ }^{9}$.

\footnotetext{
${ }^{7}$ Vale la pena recordar que incluso en el Congreso de la República, el 9 de septiembre de 1949, un poco antes del cierre decretado por Mariano Ospina Pérez, se presentó un enfrentamiento armado entre los parlamentarios, donde murió un representante liberal y varios resultaron heridos.

${ }^{8}$ Gran parte de las modalidades de tortura, desaparición, desplazamiento y asesinato fueron narradas por campesinos víctimas de la violencia, por guerrilleros y algunos funcionarios del Estado, ante la Comisión Nacional Investigadora de las Causas Actuales de la Violencia conformada mediante decreto no 0942 del 27 de mayo de 1958.

${ }^{9}$ Aunque en sus planteamientos públicos la Iglesia Católica aparentemente había sustentado un distanciamiento de la política, gran parte de su estructura institucional fue aliada fundamental en las acciones de represión adelantadas por los militares y conservadores. Tal posición en el marco de "La Violencia" corresponde tanto a las orientaciones del Papa Pio XII (reconocido anticomunista que estuvo al frente de la Iglesia católica desde 1939 hasta 1958), como a las opciones tomadas por la jerarquía eclesiástica nacional.
} 


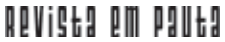

\} GUERRA Y PAZ EN COLOMBIA: INTRODUCCIÓN AL CASO DE LAS FARC - LONDOÑO, S. Q. \}

DOI $10.12957 /$ REP.2017.30375

Las acciones represivas del bloque hegemónico conservador desplaza a los campesinos hacia las ciudades creando no solo un hecho sociopolítico, sino también, y fundamentalmente, un hecho económico.

El proceso de mecanización y tecnificación del agro, junto con el monopolio de la tierra efectuados durante este periodo, generan un cambio en la estructura agraria del país no solo en cuanto a su tenencia de la tierra se refiere, sino en cuanto a la introducción de nuevas formas y relaciones de producción, que le permiten ingresarse al desarrollo capitalista bajo formas moderna y cada vez superiores de acumulación. (MARTÍNEZ et al., 1981, p. 75-76).

Con la expulsión de campesinos, la burguesía terrateniente se apropia de la tierra y desplaza la fuerza de trabajo hacia la ciudad. Según datos retomados por Guzmán (2014) presentados por la Oficina Nacional de Rehabilitación y Socorro, se calcula que entre el periodo de 1946 a 1953 miles de familias son desplazadas de sus territorios, alcanzando los 60.000 exiliados en Bogotá, 40.000 en Norte de Santander, 20.000 en Venezuela y 5.000 en Panamá. Si por un lado los latifundistas se benefician con la apropiación de las tierras abandonadas o adquiridas a muy bajo costo, por su parte, la nueva burguesía urbana dispone de fuerza de trabajo suficiente y a bajo costo para intentar fortalecer la economía industrial.

Reconociendo un peligro común en la amenaza del desplazamiento o la muerte a manos del ejército, la policía, "Los pájaros" y "Chulavitas", los campesinos y aparceros fortalecen y/o crean organizaciones de Autodefensa y guerrilleras.

\section{Violencia insurgente y lucha de clases}

La política de "tierra libre" implementada en Europa para la instauración de la llamada acumulación originaria, proceso histórico analizado por Karl Marx en El Capital (1976), puede ser equiparable a la estrategia de "tierra arrasada" utilizada por la oligarquía colombiana a finales de los años 1940. Si en Europa la combinación de acciones legales e ilegales permitió la apropiación capitalista de la tierra y desplazó hacia la ciudad a los campesinos, conformando así la nueva clase proletaria, en Colombia tal proceso de expropiación y desplazamiento no se daría sin importantes expresiones de resistencia armada.

A continuación podemos estudiar el caso de las Autodefensas Campesinas como expresiones del proceso de conciencia de un sector de la clase trabajadora, surgido de las condiciones materiales de existencia.

Según lasi $(2011 ; 2012)$, el proceso de conciencia tiene un estado inicial en el que la realidad se asume como ahistórica, individual; donde lo particular se hace universal y los individuos dominados asumen como 
propias las ideas que a través de la ideología les son impuestas por las clases dominantes. La ruptura con la dominación ideológica (que se da en la medida que avanzan las contradicciones materiales) representa la posibilidad de consolidar el proceso de conciencia, que permite reconocer el carácter histórico de la realidad, y por tanto, la posibilidad de ser transformada.

En el transcurso de construir una conciencia de clase, queda claro que la transformación social solo es posible a partir de las acciones colectivas.

O sentimento de pertença em relação a um grupo produz no indivíduo uma mudança qualitativa, se bem que ainda embrionária; o ser social subsumido pela forma individualizante se vê como parte de uma coletividade que lhe dá identidade e no interior da qual experimenta uma força que fora dele desconhecia. (IASI, 2012, p. 261-262).

lasi reconoce el miedo como fundamental para la constitución de colectividades y organizaciones, en una primera forma de conciencia. La agrupación de individuos que comparten la vulnerabilidad frente a una fuerza externa permite que entre sí garanticen su propia defensa. En esta misma línea argumentativa, al intentar explicar la conformación de grupos de Autodefensa, Germán Guzmán dice:

Por simple impulso de conservación el campesino perseguido integra un grupo que ciertamente desconoce: el de la lucha. En él se refugia, lo respalda, lo ayuda, hasta lo ama aunque trágicamente, como algo que colma el vacío de seguridad social que ha perdido. (GUZMÁN apud GUZMÁN; BORDA; UMAÑA, 2014).

Estos tipos de organización pueden ser temporales, mientras es eliminada la fuerza que provoca el miedo, o por el contrario, pueden dar un salto cualitativo y organizarse de manera permanente, pasando de una conciencia en sí a una conciencia para sí.

A consciência em si representa ainda a consciência que se baseia na vivência das relações imediatas, não mais do ponto de vista do indivíduo, agora do grupo, da categoria, e pode evoluir até a consciência de classe. Ela é parte fundamental da superação da primeira forma da consciência, por tanto, da alienação; no entanto, seu pleno desenvolvimento ainda evidencia traços da antiga forma ainda não superados. (IASI, 2011, p. 30).

El proceso de desarrollo de conciencia es un tránsito que conserva viejas características, pero que al mismo tiempo demuestra construcciones inéditas; situación equivalente puede ser evidenciada en el momento en que las Autodefensas Campesinas reivindican sus derechos, y se disponen a la defensa armada de los mismos. 
Surge como secuela natural el grupo armado ofensivo-defensivo para un empeño de muchos días, que se cohesiona en razón directa de los móviles vitales. Es este momento en que el campesino precisa nítidamente su ideal: lucha por el hogar, el honor, la vida, lo suyo entrañable, su mundo, su partido, su querencia. Él no desató la guerra, pero acepta el reto y es bárbaro en vindicta. (GUZMÁN apud GUZMÁN; BORDA; UMAÑA, 2014).

Con armas rudimentarias, los campesinos organizados en las Autodefensas se enfrentan a los ataques conservadores liderados por el poder latifundista que reproduce un desarrollo capitalista oligárquico; sin embargo, la acción militar campesina es de carácter defensivo. Las comunidades más avanzadas en su proceso de conciencia construyen formas de organización que, tanto en la producción como en las relaciones políticas y de la vida cotidiana, fortalecen la protección y el antagonismo con los verdugos.

El relato de un campesino (que con el tiempo se torna guerrillero) evidencia los motivos articuladores de la organización:

[...] siendo que por ese entonces pasábamos del trabajo y de la paz a la violencia y persecución por el único pecado de ser liberales. Y como entonces ni siquiera se hablaba de guerrilla, no sabíamos defendernos ni dónde meternos para alejarnos de tanta ferocidad, y entonces como siguieron llegando pobres familias a quienes habían matado a personas queridas para ellas, o los habían maltratado, o les habían robado lo que tenían o incendiado sus pequeñas propiedades; y entonces ya en compañía del amigo Borja, se empezó a organizar la manera de defender esas pobres familias y a los que no teníamos más amparo que el de ellos, y a ver la manera de estar protegidos y lejos de tanto mal y fue así como por pura necesidad y con grandes sacrificios lograron reunir unas escopeticas todas remendadas e inseguras. [...] éramos muchos los que nos habíamos reunido en busca de refugio y protección, muy especialmente para los niños, para los ancianos, para las mujeres y, en general, todos los que habíamos tenido que huir a la persecución sectaria de los Policías, del Ejército, de los godos, y pájaros, que eran los mismo godos pero más malos, y hasta de los curas que habían convertido la religión en persecución política. (GUZMÁN apud GUZMÁN; BORDA; UMAÑA, 2014).

Su carácter defensivo es uno de los principales elementos que confirman los avances y límites de ese tipo de conciencia. Por un lado, ya es una forma de organización que abandona la idea de individuo autosuficiente y que reconoce en sus pares una población copartidaria de penurias; la misma población acompañante que en determinadas circunstancias puede ser garante de protección. La identificación de intereses antagónicos contra otros grupos sociales (en este caso, sectores latifundistas, el Estado y sus fuerzas represivas) fortalecen convicciones políticas en los campesinos, proporcionándoles una forma más definida y consciente de las contradicciones vividas. 


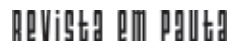

\} GUERRA Y PAZ EN COLOMBIA: INTRODUCCIÓN AL CASO DE LAS FARC - LONDOÑO, S. Q. \}

DOI 10.12957/REP.2017.30375

En el momento decisivo del transcurso de la conciencia en sí, hacia la conciencia para sí, algunas Autodefensas desaparecen y otras avanzan. Así entonces, al desaparecer el elemento articulador (el miedo), el proceso organizativo se puede disolver, o por el contrario, puede constituir un grado más elevado de cohesión, en el que se establecen nuevos intereses colectivos encaminados a una posible conciencia de clase.

Un caso típico de la estructura de una región de Autodefensas es la región del Pato. En ella se daban poderes ejecutivos a un dirigente de la comunidad, a otro se le asignaba el cargo de parcelador de tierras (quienes debían además dirimir los conflictos de linderos) y a un tercero el rol de secretario, con funciones de publicidad e información. Existía además un Consejo con representantes veredales y con una participación adicional de la organización partidista, la de los jóvenes y la de las mujeres. Estas aún hoy, debían además animar las organizaciones cooperativas, las escuelas y adquirir máquinas de coser. Otras formas de acción comunitaria se desarrollaban en torno a una biblioteca pública, cursos de educación política obligatoria, cursos de alfabetización y finalmente, una maquinaria para procesar la caña de azúcar. (GILHODES apud PIZARRO, 1989, p. 26).

Los procesos que continúan el desarrollo organizativo evidencian la superación del elemento inicial de articulación que era el miedo, encontrando otras características que cohesionan aún más el grupo, profundizando su acción y perspectiva política. Al reconocer los intereses de las clases dominantes que actúan contra campesinos y jornaleros, las Autodefensas acuerdan proyecciones políticas orientadas hacia la transformación social y la toma del poder del Estado, superando el carácter defensivo sobre el cual surgen; es así que aparece la guerrilla como actor relevante en la lucha de clases, ahora con una estrategia de ofensiva y ataque ${ }^{10}$.

Ante la incapacidad de eliminación física de las Autodefensas a través de la violencia, el Estado opta por una aparente solución pacífica y concertada al enfrentamiento político-militar; así, desde el Gobierno del General Rojas Pinilla (1953-1957) se realizan acuerdos con diferentes grupos de Autodefensas y guerrillas liberales, las cuales, en poco tiempo serían traicionadas y reprimidas. El caso icónico de esta situación para los años 50 fue el de las guerrillas liberales de los Llanos Orientales, lideradas por Guadalupe Salcedo.

En apariencia, el régimen militar de Gustavo Rojas Pinilla pondría fin al enfrentamiento, levantando la consigna de "No más sangre, no más depredación; paz, justicia y libertad para todos"; sin embargo, y pese a la amnistía y las respectivas desmovilizaciones de guerrillas liberales, la acción coercitiva continúa cumpliendo su papel preponderante.

\footnotetext{
${ }^{10}$ Una película, considerada un clásico, que muestra parte del proceso de transición de Autodefensas a Guerrillas es "Rio Chiquito" producida por Jean Pierre Serget y Bruno Muel (1964).
} 


\section{meVistg am palth}

\} GUERRA Y PAZ EN COLOMBIA: INTRODUCCIÓN AL CASO DE LAS FARC - LONDOÑO, S. Q. \}

DOI $10.12957 /$ REP.2017.30375

En este periodo el papel de las fuerzas militares pasó a cobrar mayor relevancia debido al crecimiento y cualificación de movimientos y organizaciones sociales, partidos políticos de oposición, movimientos de Autodefensa y guerrilleros; todos ellos combatidos bajo el ideario de enemigo interno y la doctrina contrainsurgente.

A partir de la Dictadura de Rojas Pinilla, las Fuerzas Armadas dejan de tener un papel subsidiario dentro de la política nacional y pasan a convertirse en uno de sus elementos esenciales. En esta transformación inciden tres factores que están relacionados entre sí: la transición del bipartidismo hacia un régimen de coalición, el conflicto que enfrenta a los principales actores de las clases dominantes con el movimiento popular y la izquierda, y la evolución de las relaciones entre las Fuerzas Armadas y los Estados Unidos. (MUNERA, 1998, p. 145)

Con recursos y asesoría militar norteamericana (tanto a Rojas Pinilla como al Frente Nacional) se hacen cada vez más recurrentes los ataques hacia Autodefensas como "Rio Chiquito" y "Marquetalia", denominadas por el gobierno conservador como "Repúblicas Independientes", que debían ser eliminadas en tanto que en estas se encontraba "el germen comunista".

Sin embargo, el proceso de conciencia de clase de los trabajadores se encuentra en un punto de no retorno, pues los grupos de Autodefensa que consiguen sobrevivir ante de la intensificación de la violencia Estatal, transitan por un proceso de articulación entre sí, que va desde finales de los años 1950 hasta la mitad de la década de 1960. Autodefensas influenciadas o articuladas al Partido Comunista buscan los elementos comunes de identidad; Marquetalia, Villarica, Riochiquito, El Pato, Guayabero, se reúnen en el sur del Tolima y plantean una plataforma y estrategia para combatir la dominación de liberales y conservadores, conformando así el Bloque de las Guerrillas del Sur, protoforma de las Farc ${ }^{11}$.

Con el lanzamiento del "Programa Agrario de los Guerrilleros" el 20 de julio de 1964, plataforma de lucha de las Farc, queda claro el tránsito por los diferentes momentos del proceso de conciencia, partiendo de la articulación de individuos que buscan garantizar su propia defensa, pasando por el posterior reconocimiento de intereses políticos y económicos que antagonizan con otras fuerzas, hasta elevar su perspectiva política a un nivel de clase, donde se tiene como principal objetivo la transformación estructural de las relaciones sociales de producción, fundamentalmente aquellas establecidas en el campo.

El ciclo se cierra y toma una forma definida; en síntesis, con el abordaje histórico es posible observar que algunos grupos de Autodefensa dan el salto cualitativo hacia organizaciones guerrilleras, abandonan el

\footnotetext{
11 Ver Arenas (1972), Marulanta (s.f.), Guaracas (2015). A partir de la VIII Conferencia Guerrillera, realizada en 1982, a las siglas Farc se agregan Ejército del Pueblo (EP).
} 
interés particular de enfrentar el enemigo generador de miedo, para pasar a proyectar la defensa de los intereses de los campesinos pauperizados en el territorio nacional; es decir que la metamorfosis Autodefensa-Guerrilla constituye un proceso de conciencia de clase que se manifiesta en el uso de las armas contra la clase antagónica, y al Estado como su principal representante.

Desde 1958, se gesta el Frente Nacional como acuerdo bipartidista (Liberal-Conservador) para retomar el poder que de forma coordinada había sido delegado al general Rojas Pinilla. El supuesto retorno a la democracia será la bandera con la que los partidos tradicionales retoman la administración del Estado.

El acuerdo de elites del Frente Nacional sintoniza la política y la economía colombiana con las medidas orientadas por el capital monopolista, orientadas para la región latinoamericana a través de la "Alianza para el Progreso", en un intento de modernización continental. La modernización institucional del Estado y la producción se implementan para garantizar el ingreso de Colombia a la economía de los monopolios en la etapa del capitalismo tardío ${ }^{12}$. Ahora bien, además las medidas de orden económico, propias de las transformaciones del modo de producción capitalista, también se intensifican las medidas político-represivas manifiestas en la Doctrina de Seguridad Nacional correspondiente a la polarización de la Guerra Fría. Con preponderancia, en Colombia se destacan las acciones inscritas en el Plan LASSO (Latin American Security Operation) a través del cual se combaten diferentes formas de organización de las clases subalternas, y no solo las estructuras guerrilleras.

En adelante y hasta el siglo XXI, el enfrentamiento político se desarrolla fundamentalmente a través de la guerra y el ejercicio coercitivo por parte del Estado. A pesar de diversos procesos de paz con las Farc-EP, el incumplimiento del Estado y el fortalecimiento de sectores oligárquicos, ahora aliados al narcotráfico y al paramilitarismo, impidieron la salida negociada al enfrentamiento militar, y por el contrario radicalizaron aún más la doctrina contrainsurgente. ${ }^{13}$

\section{Acabar la guerra para democratizar el país}

El carácter contradictorio de la guerra para los sectores hegemónicos divididos en fracciones más reaccionarias y moderadas, sumado a la

\footnotetext{
${ }^{12}$ El caso del café y petróleo incorporados a la dinámica del capital monopolista se puede consultar en Jorge Villegas (1976) y Luis Eduardo Nieto A. (1992).

${ }_{13} \mathrm{Tal}$ vez el caso más conocido fue el de la Unión Patriótica (UP), partido político que surge como resultado de los diálogos de paz de la Uribe-Meta, donde las Farc-EP empiezan el tránsito a la vida política legal para disputar el poder del Estado. Una vez iniciado el tránsito hacia la política legal en alianza con amplios sectores sociales, el paramilitarismo y las fuerzas estatales desatan un plan de exterminio conocido como "El Baile Rojo" a través del cual asesinaron más de 4000 militantes de la UP. El caso del exterminio puede ser visto en "El Baile Rojo. Memoria de los silenciados" de Yesid Campos.
} 


\section{mevistg aाm paltg}

\} GUERRA Y PAZ EN COLOMBIA: INTRODUCCIÓN AL CASO DE LAS FARC - LONDOÑO, S. Q. \}

DOI $10.12957 /$ REP.2017.30375

capacidad militar de la insurgencia y a las exigencias de las clases subalternas por la democratización de la vida nacional, abrió los diálogos de paz como alternativa de participación política para los sectores históricamente excluidos $^{14}$. Durante los últimos 6 años (2012-2017) se adelantaron Diálogos en La Habana entre las Farc-EP y el gobierno de Juan Manuel Santos, al tiempo que se inició un proceso de paz con el ELN.

Si bien en la mayoría de los casos los diálogos de paz han sido utilizados por las clases hegemónicas para rediseñar su política económica y militar en beneficio del gran capital, la apertura de un debate político y la búsqueda de salidas concertadas a las causas que originaron la guerra abren un campo contradictorio que posibilita y exige la reestructuración del Estado, poniendo en primer plano la lucha política y no militar, disminuyendo intensidad en el ejercicio coercitivo. Las clases y fracciones de clases enfrentadas en el campo militar, ahora generan las condiciones para enfrentarse en los escenarios legales de la institucionalidad y la lucha de masas.

Según el "Acuerdo general para la terminación del conflicto y la construcción de una paz estable y duradera" suscrito en 2012 entre las Farc-EP y el gobierno de Juan Manuel Santos, al igual que el Acuerdo Final alcanzado en 2016, el orden político, militar y económico se encuentra con evidentes posibilidades de reestructuración, lo que implica transformaciones al interior del Estado, y un nuevo contexto en la lucha de clases.

Dos posiciones diametralmente opuestas se enfrentaron en la mesa de La Habana (Farc-EP y Estado) y ahora se trasladan al campo político legal, donde las Farc lanzan la propuesta de nuevo partido político; sin embargo, la contradicción fundante de la lucha hegemónica y contrahegemónica no se resuelve entre estos dos actores, sino que comprende otros sectores que van desde el reaccionarismo oligárquico, pasando por proyectos modernizantes, hasta propuestas alternativo-revolucionarias. El marco de alianzas y enfrentamientos se reconfigura en un claro enfrentamiento por ganar la hegemonía.

El enfrentamiento de estas posiciones (que implica la aproximación entre fracciones internas y la agudización de la lucha con otras), puede arrojar reformas de gran impacto en las que existan acuerdos mínimos para el desarrollo político y económico del país. El choque de proyectos societarios puede generar una síntesis que, para el caso colombiano se debe sustentar en una ampliación de la democracia con reformas políticas y el redireccionamiento de la política económica, que puede conducir a un nuevo tipo de desarrollo agrario y a una revisión de la economía de mercado.

Es evidente que los resultados inmediatos de los diálogos de paz no superan el orden capitalista, sino que se limitan a reformar algunas con-

\footnotetext{
${ }^{14}$ Desde mitad del siglo XX se presentaron varias experiencias de dialogo entre las guerrillas (liberales y comunistas) y el Estado colombiano. Los diálogos realizados con las Farc se han presentado en las décadas de 1980, 1990 y 2000.
} 


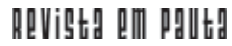

\} GUERRA Y PAZ EN COLOMBIA: INTRODUCCIÓN AL CASO DE LAS FARC - LONDOÑO, S. Q. \}

DOI 10.12957/REP.2017.30375

diciones particulares propias del capitalismo periférico en Colombia. No obstante, las "transformaciones" que allí se pueden presentar representan grandes avances que favorecen a la clase trabajadora, dado que esta ha sido la principal víctima del orden vigente, sea por los impactos de la guerra o por la exclusión y pauperismo a la que ha sido sometida.

De esa manera, como resultado del enfrentamiento (no armado) entre las clases y fracciones de clases, las políticas sociales cobran importancia, exigiendo capacidad política y técnica de las organizaciones que se enfrentan. Esto quiere decir que la conquista de derechos (sociales, políticos, económicos, culturales y ambientales) corresponde a la correlación de fuerzas que se establezca en el nuevo escenario político donde se haya superado la guerra. Todo indica que nuevos actores ocuparán viejos espacios, al tiempo que nuevos espacios serán creados en el recorrer de la lucha política; de ello da cuenta el Estatuto de Oposición y la implementación del punto II del Acuerdo de Paz (participación política). Desde ya se avistan contradicciones inéditas en el parlamento y diversas instancias estatales, en los medios de comunicación, además de la organización y movilización popular, que cobra mayor protagonismo.

Pasados más de 50 años en el último ciclo de guerra, al parecer la lucha de clases ha llegado a un nuevo nivel en el que no solo se hace necesario poner fin al enfrentamiento militar, sino que además se debe construir un proyecto de país que reconozca intereses diferenciados de las partes enfrentadas; esto no quiere decir que se establece un acuerdo social que elimine diferencias políticas propias del modo de producción capitalista, pues la estructura fundamental del capital aún se mantiene en pie.

El fin de la guerra no constituye el fin del capitalismo periférico en Colombia, sin embargo, la superación del carácter coercitivo que ha caracterizado al Estado brinda enormes posibilidades para una nueva correlación de fuerzas; el contexto vivenciado a partir de los diálogos de paz coloca como alternativa posible la construcción de un nuevo proyecto societario en el que se abran caminos hacia la democratización política y económica, escenario en el cual se pueden fortalecer propuestas que proyectan la superación del modo de producción capitalista, donde ciertamente se pueda inscribir el tránsito de las Farc-EP a la vida política legal. 


\section{Referencias}

ARENAS, J. Diario de la resistencia de Marquetalia. Colombia: Abejón Mono, 1972.

ARICÓ, J. Marx y América Latina. Lima: Centro de Estudios para el Desarrollo y la Participación, 1980.

CAMPOS, Y. El Baile Rojo. Memoria de los silenciados (documental). Colombia: JYC Comunicación, 2003.

COLOMBIA. Acuerdo final para la terminación del conflicto y la construcción de una paz estable y duradera. Disponível em <https:// www.mesadeconversaciones.com.co/sites/default/files/24-1480106030.111480106030.2016nuevoacuerdofinal-1480106030.pdf>. Acesso em: 13 abr. 2017.

. Acuerdo general para la terminación del conflicto y la construcción de una paz estable y duradera. Disponível em: <https:// www.mesadeconversaciones.com.co/documentos-y-comunicados $>$. Acesso em: 20 fev. 2016.

CUEVA, A. El desarrollo del capitalismo en América Latina. México: Siglo XXI, 1977.

FERNANDES, F. Capitalismo dependente e classes sociais na América Latina. São Paulo: Global, 2009.

GARCíA, A. Dinámicas de las reformas agrarias en América Latina. Bogotá: La Oveja Negra, 1972.

GUARACAS, J. Así nacieron las Farc. Memorias de un comandante marquetaliano. Colombia: Ocean Sur, 2015.

GUZMÁN, G.; BORDA, O.; UMAÑA, E. La violencia en Colombia. Bogotá: Punto de lectura, 2014.

IASI, M. As metamorfoses da consciência de classe. São Paulo: Expressão Popular, 2012.

- Ensaios sobre consciência e emancipação. São Paulo: Expressão Popular, 2011.

MANDEL, E. O capitalismo tardio. São Paulo: Os Economistas, 1982.

MAQUIAVELO, N. El príncipe. Bogotá: Editorial Bedout, 1986.

MARIÁTEGUI, J. Sete ensaios de interpretação da realidade peruana. São Paulo: Expressão Popular, 2010.

MARINI, R. O ciclo do capital na economia dependente. In: FERREIRA, C.; OSORIO, J.; LUCE, M. (Org.). Padrão de reprodução do capital. São Paulo: Editorial Boitempo, 2012. 
MARTíneZ, M. et al. Historia del trabajo social en Colombia 1900-1975. Bogotá: Tecnilibros, 1981.

MARULANDA, M. Cuadernos de campaña. Disponível em: <http:// www.rebelion.org/docs/68099.pdf >. Acesso em: 12 fev. 2016.

MARX, K. El capital. Crítica de la economía política. Bogotá: Fondo de Cultura Económica, 1976.

MONCAYO, V. Hacia la verdad del conflicto: insurgencia guerrillera y orden social vigente. In: Conflicto social y rebelión armada en Colombia. Ensayos críticos. Bogotá: Gentes del Común, 2015.

MUNERA, L. Rupturas y continuidades. Poder y movimiento popular en Colombia 1968-1988. Bogotá: Universidad Nacional de Colombia, 1998.

NIETO, L. El café en la sociedad colombiana. Bogotá: El Áncora Editores, 1992.

PIZARRO, L. Los orígenes del movimiento armado comunista en Colombia (1949-1966). Revista Análisis Político, Bogotá: Universidad Nacional de Colombia, n. 7, 1989.

SERGET, J., MUEL, B. Rio Chiquito. 1965. Disponível em: <https:// www.youtube.com/watch?v=OeMRiZgM5_M>. Acesso em: 13 abr. 2017. VILLEGAS, J. Petróleo colombiano, ganancia gringa. Bogotá: Peñaloza y Cia. Ltda., 1976.

Recebido em 17 de abril de 2017.

Aprovado para publicação em 28 de agosto de 2017.

DOI 10.12957/rep.2017.30375

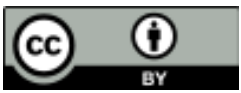

A Revista Em Pauta: Teoria Social e Realidade Contemporânea está licenciada com uma Licença Creative Commons Atribuição 4.0 Internacional. 